\title{
DESPRENDIMIENTO SEROSO MACULAR BILATERAL COMO FORMA DE PRESENTACIÓN DE LINFOMA B DIFUSO DE CÉLULA GRANDE
}

\section{DIFFUSE LARGE B CELL LYMPHOMA PRESENTING WITH A BILATERAL SEROUS MACULAR DETACHMENT}

\author{
RECHE-SAINZ JA ${ }^{1}$, PERAL-ORTIZ DE LA TORRE MJ ${ }^{1}$, CARPIO-BAILÉN R ${ }^{1}$, \\ TOLEDANO-FERNÁNDEZ N ${ }^{1}$
}

\section{RESUMEN}

Caso clínico: Un varón de 42 años fue atendido por pérdida visual bilateral subaguda. Como antecedentes presentaba una hepatitis $\mathrm{C}$ crónica activa y un síndrome de Evans. Mediante funduscopia se observaron múltiples focos de desprendimiento neurosensorial y de EPR en ambas polos posteriores. A los pocos días empeoró su estado general (fiebre alta y múltiples adenopatías). La biopsia de las adenopatías laterocervicales objetivó un linfoma B difuso de células grandes. Se le trató con quimioterapia y experimentó una paulatina reaplicación de los focos de desprendimiento seroso con mejoría visual progresiva.

Discusión: El desprendimiento seroso macular bilateral puede ser una manifestación precoz de un linfoma B difuso de célula grande. El curso de estas lesiones intraoculares puede ser favorable con la remisión del linfoma.

Palabras clave: Retina, mácula, desprendimiento seroso, linfoma, linfoma B difuso de célula grande.

\section{ABSTRACT}

Clinical case: A 42 year-old male was assessed for a subacute, bilateral and progressive visual loss. His medical history included chronic hepatitis $\mathrm{C}$ infection and Evans syndrome. On fundal examination, multiple areas of neurosensorial and retinal pigmented epithelium detachment were observed in the region of both macula. A few days later, his general health deteriorated and he was noted to have a high fever and adenopathy. Biopsy of an enlarged lateral cervical lymph node demonstrated the existence of a diffuse large B cell lymphoma. After several cycles of chemotherapy, he experienced a progressive and bilateral improvement of his vision, which was accompanied by a reattachment of the previously detached areas.

Discussion: A bilateral and serous macular detachment may be the initial manifestation of a diffuse large B cell lymphoma. The prognosis of these retinal lesions may be favourable if lymphoma remission is achieved (Arch Soc Esp Oftalmol 2007; 82: 559-562).

Key words: Retina, macula, serous detachment, lymphoma, diffuse large B cell lymphoma.

\footnotetext{
Recibido: 31/5/06. Aceptado: 17/7/07.

Hospital de Fuenlabrada. Madrid. España.

${ }^{1}$ Licenciado en Medicina.

Correspondencia:

José Alberto Reche Sainz

C/. Guzmán el Bueno, 98, 6. ${ }^{\circ} \mathrm{D}$

28003 Madrid

España

E-mail: jalbres@yahoo.es
} 


\section{INTRODUCCIÓN}

Los tumores intraoculares pueden cursar con desprendimientos serosos de la retina. Son las metástasis coroideas de los carcinomas de mama y pulmón las que más habitualmente se asocian a este tipo de desprendimientos. Sin embargo, la afectación uveal en los casos de linfomas sistémicos es muy poco frecuente (1). Por otra parte, los desprendimientos serosos maculares suelen estar normalmente causados por etiologías no neoplásicas, como son la coroidopatía serosa central en los adultos jóvenes y la degeneración macular asociada a la edad en las edades avanzadas.

Se presenta un caso de un linfoma tipo B en adulto joven que debutó con pérdida visual bilateral por desprendimiento macular bilateral.

\section{CASO CLÍNICO}

Un varón de 42 años de edad acude a Urgencias por disminución bilateral y progresiva de visión de varias semanas de evolución.

Como antecedentes personales destacaba la existencia de una hepatopatía crónica por virus $\mathrm{C}$ y un síndrome autoinmune de Evans (púrpura trombocitopénica autoinmune con anemia) de larga evolución, que había requerido esplenectomía hacía 20 años. El tratamiento de mantenimiento era de $30 \mathrm{mg}$ de prednisona oral en días alternos.

En la exploración oftalmológica, la agudeza visual mejor corregida era en OD 0,3 y en OS 0,2.
Biomicroscópicamente presentaba una catarata subcapsular posterior $1+$ en OD y de $2+$ en OS. Mediante funduscopia se observaron múltiples áreas de desprendimiento neurosensorial y de epitelio pigmentario de la retina (EPR) en el polo posterior de ambos ojos, así como unas pequeñas lesiones blanquecinas, redondeadas, discretas y escasas en la retina ecuatorial de ambos ojos (fig. 1). Además, en OS había otras lesiones periféricas cicatriciales con pigmentación. La tomografía óptica de coherencia (OCT) puso de manifiesto los desprendimientos que afectaban a la mácula de ambos ojos (fig. 2).

Se le indicó una angiofluoresceingrafia, que no se llegó a realizar porque a los 2 días el paciente fue ingresado por un cuadro de fiebre alta, adenopatías laterocervicales y diarrea persistente. Fue tratado de forma empírica con cefotaxima y corticoterapia, pero evolucionó desfavorablemente presentando dificultad respiratoria con progresivo deterioro de su estado general. Mediante TAC se comprobó la existencia de un gran ensanchamiento mediastínico, y la biopsia de las adenopatías cervicales evidenció un linfoma B difuso de célula grande con marcador CD20 +. Con el diagnóstico de linfoma no Hodgkin $\mathrm{B}$ difuso de célula grande en estadio II E, se le administraron 6 ciclos de quimioterapia $\mathrm{CHOP}$ y rituximab. A lo largo del tratamiento quimioterápico (sobre todo a partir del 3. ${ }^{\text {er }}$ ciclo), el paciente ya experimentó una franca mejoría visual, objetivándose la reaplicación progresiva de todos los focos de desprendimiento sensorial y de EPR, quedando cicatrices retinocoroideas con redistribución de pigmen-

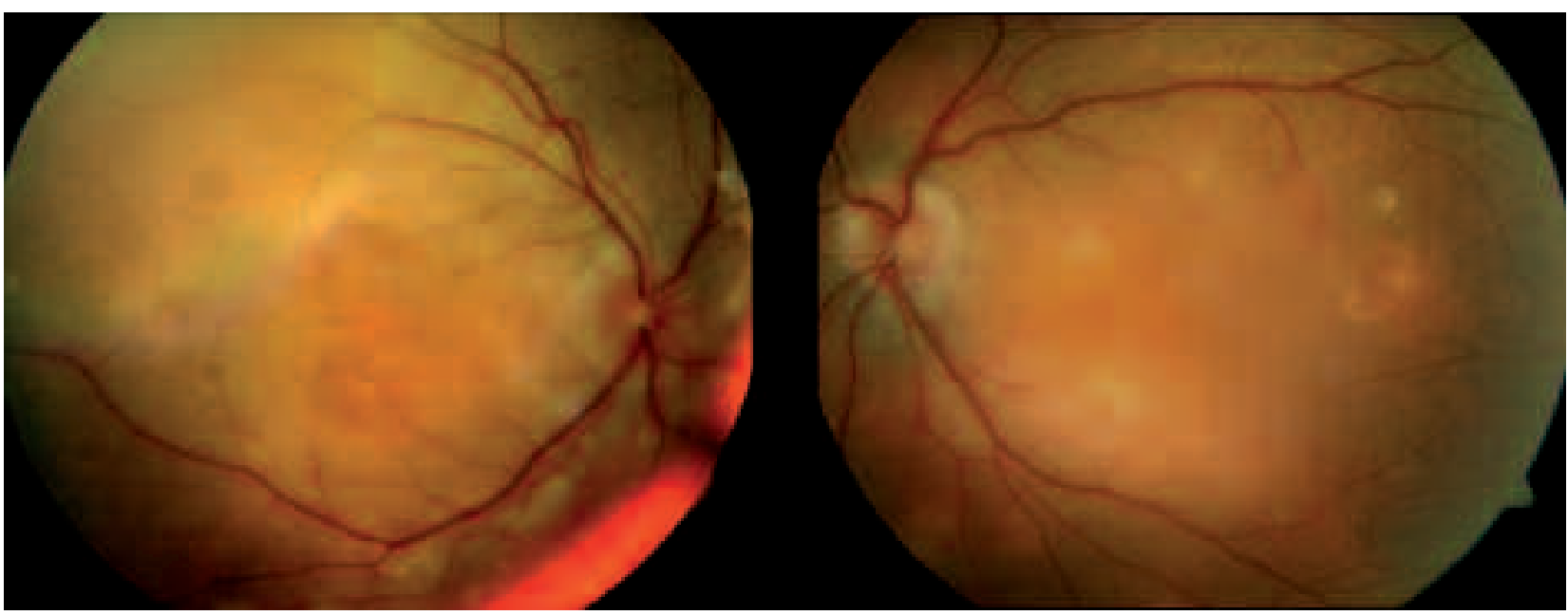

Fig. 1: Aspecto funduscópico inicial. Varios focos de desprendimiento de EPR de OD y desprendimiento neurosensorial difuso en $O S$. 


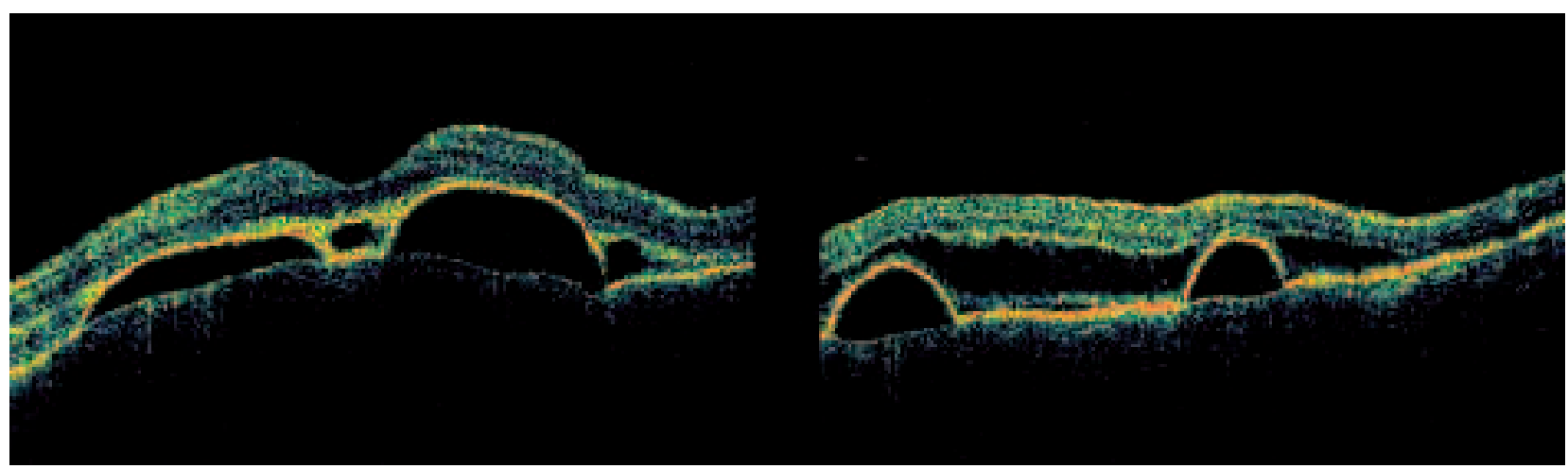

Fig. 2: Aspecto tomográfico inicial de ambas máculas mediante OCT congruente con los hallazgos oftalmoscópicos.

to. A los 6 meses de evolución tras la quimioterapia, se confirmó la remisión completa del linfoma por TAC y gammagrafía, y las retinas estaban aplicadas y las antiguas lesiones exudativas tenían un aspecto cicatricial e inactivo (fig. 3). Mediante OCT se corroboró la resolución de los desprendimientos (fig. 4). La AV era de 0,7 en OD y de 0,6 en OS y el paciente está pendiente de intervención de catarata.

\section{DISCUSIÓN}

Dentro de los trastornos linfoproliferativos, la afectación ocular es mucho más habitual en las leucemias $(28 \%)$ que en los linfomas sistémicos $(7 \%)$ (2). Se han descrito como manifestaciones oculares de los linfomas sistémicos, la infiltración coroidea y de iris, y más raramente uveitis anterior y pseu- dohipopion (2). También pueden aparecer, de forma más inespecífica, hemorragias y exudados algodonosos por la anemia o la trombocitopenia derivadas del trastorno linfoproliferativo.

Este paciente estaba inmunodeprimido por presentar una púrpura trombocitopénica autoinmune con una infección viral activa por hepatitis $\mathrm{C}$, circunstancia que puede favorecer la infiltración linfomatosa del tracto uveal. Asimismo los síntomas visuales referidos se asociaban predominantemente a la presencia de desprendimientos serosos focales y múltiples en ambas máculas. En las retinas periféricas se observaron lesiones pequeñas blanquecinas profundas compatibles con infiltración coroidea por el linfoma. Estos hallazgos precedieron a la instauración y diagnóstico del cuadro sistémico de linfoma difuso B de célula grande. La progresiva desaparición de los desprendimientos serosos fue paralela a la remisión del linfoma.

Fig. 3: Aspecto funduscópico tras los ciclos de quimioterapia: aplanamiento de la retina en ambos polos posteriores con lesiones cicatriciales residuales. 


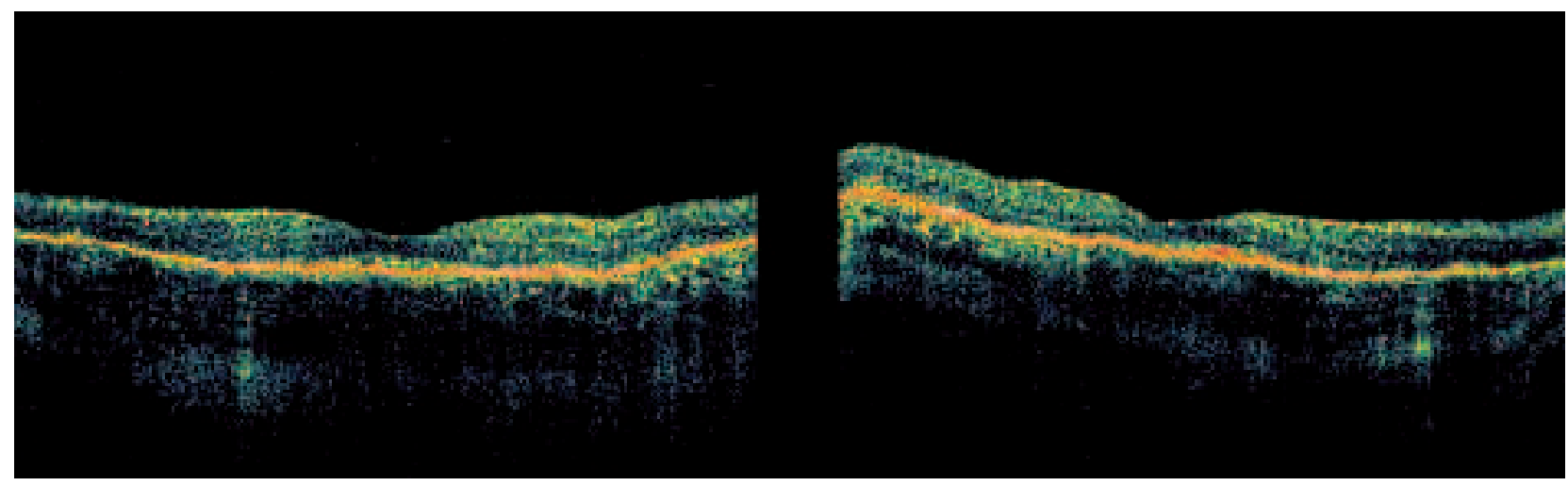

Fig. 4: Aspecto tomográfico de ambas máculas mediante OCT tras los ciclos de quimioterapia. Se corroboró la total reaplicación de ambas retinas.

Son muy pocas las referencias en la literatura a casos de desprendimientos serosos maculares asociados a linfomas de origen sistémico. Se han descrito casos aislados de linfoma Hodgkin, linfoma T asociado al virus de Epstein-Barr (3), macroglobulinemia de Waldeström (4) y un caso de linfoma noHodgkin tras tratamiento con nitrato de galio (5), que se manifestaron ocularmente con desprendimientos serosos de predominio macular.

El desprendimiento seroso macular bilateral puede ser, por lo tanto, la manifestación ocular de un linfoma B difuso de célula grande. Dicha alteración puede aparecer de forma muy precoz e incluso anteceder a la instauración del cuadro sistémico. El curso evolutivo de estas alteraciones retinianas es favorable si se logra la remisión del linfoma tras la quimioterapia.

\section{BIBLIOGRAFÍA}

1. O'Keefe JS, Sippy BD, Marin DF, Holden JT, Grossniklaus HE. Anterior chamber infiltrates associated with intraocular systemic lymphoma. Ophthalmology 2002; 109; 253-257.

2. Spaide RF, Goldbaum M, Wong DW, Tang KC, Iida T. Serous detachment of the retina. Retina 2003; 23: 820846.

3. Cochereau I, Hannouche D, Geoffray C, Teoblanc M, Hoang-Xuan T. Ocular involvement in Epstein-Barr virusassociated T-cell lymphoma. Am J Opthalmol 1996; 121: 322-324.

4. Pilon AF, Rhee PS, Messner LV. Bilateral, persistent serous macular detachments with Waldenström's macroglobulinemia. Optom Vis Sci 2005; 82: 573-578.

5. Moon SJ, Han DP. Acute bilateral serous macular detachment associated with gallium nitrate in a patient with nonHodgkin lymphoma. Retina 2005; 25: 212-214. 